\title{
Cuando calla Sherezada: elogio del cliffhanger y los "finales" femeninos
}

\author{
Ana Elena GonZÁLEZ TREVIÑo \\ Universidad Nacional Autónoma de México
}

En memoria de Elisabeth Siefer,

querida colega y maravillosa cuentacuentos

\begin{abstract}
En este artículo se explora el significado del silencio como estrategia narrativa con referencia especial a Las mil y una noches. Según Foucault, en el contexto académico patriarcal, el discurso es la norma, aunque sea violento y excluyente, mientras que guardar silencio resulta antitético y débil. Por el contrario, el silencio femenino es una especie de norma implícita en diversos contextos culturales. Sin embargo, Sherezada utiliza el silencio estratégicamente y lo convierte en un poder a través de la suspensión deliberada de la narración. Si esta acción se extrapola al ámbito literario y cultural en general, se observa que, como ejemplo típico, novelas y telenovelas posponen los finales de un modo análogo en una especie de seducción que se ha explotado e interpretado repetidamente.
\end{abstract}

PALABRAS ClAVE: silencio, suspenso, diferimiento, Las mil y una noches, cliffhanger.

This article explores the meaning of silence as narrative strategy with special reference to the Arabian Nights. Foucault states that, within a patriarchal academic context, discourse is the norm, despite its violent and excluding character, while silence is considered weak and antithetical. Contrariwise, feminine silence is a kind of implicit norm in different cultural contexts. Sherezade, however, uses silence strategically and in a way that empowers her through the deliberate suspension of narration. If this is extrapolated to literature and culture in general, novels and soap operas, as typical examples, postpone endings similarly in a kind of seduction which has been repeatedly exploited and interpreted.

KEY WORDS: silence, suspense, deferral, Arabian Nights, cliffhanger.

La relación dinámica que existe entre la discursividad y el silencio pone de manifiesto las relaciones de poder que están en juego en distintos contextos, por ejemplo en cuanto al género, la autoridad intelectual y la posición social. De la academia a la recámara, la administración deliberada tanto de la discursividad como del silencio permite 
el reposicionamiento del sujeto enunciador y una redistribución de fuerzas que resulta por demás interesante tanto para el literato como para el historiador cultural. La herramienta narrativa del suspenso, entendido literalmente como una suspensión de la actividad discursiva, es la que se explorará a continuación en el contexto de los finales diferidos, a partir del Orden del discurso de Foucault, como telón de fondo y a manera de analogía teórica con el modelo de Sherezada en Las mil y una noches. ${ }^{1}$

En su famoso discurso inaugural en el Collège de France en 1970, cuando asumió la cátedra de la historia de los sistemas de pensamiento, Michel Foucault explica provocadoramente que quisiera no tener que empezar, que preferiría ser "una laguna en el azar del desarrollo [del discurso], el punto de su desaparición posible" (Foucault: 1). Foucault preferiría permanecer callado y esperar, pues sostiene que el discurso irremediablemente conlleva una violencia, un despojo, un ejercicio de poder que excluye, censura y cancela. La voluntad de verdad del discurso, dice, "tiende a ejercer sobre los otros discursos... una especie de presión y... un poder de coacción”. Es, en otras palabras, "una prodigiosa maquinaria destinada a excluir" (5). Y por eso "[e]s necesario concebir el discurso como una violencia que se ejerce sobre las cosas" (14).

No olvidemos que Foucault, sin embargo, está hablando del contexto particular de ese momento. El Collège de France es uno de los máximos estrados institucionales, un centro generador y custodio del conocimiento, garante de la legitimidad de las palabras que ahí se pronuncian, un foro masculino y patriarcal, autoritario y experto en el ejercicio de la exclusión. Cuando Foucault expresa su deseo de callar mientras habla, está realizando un gesto que sugiere la posibilidad de desmontar el aparato dogmático generado en gran medida por las instituciones, y reforzado por la cultura impresa. Las academias y los libros aspiran a definir una preceptiva fija e inmutable, capaz de producir un conocimiento estable, pero el sistema de autoridades en el que se basan conduce a un anquilosamiento estéril y miope. Callar en este contexto sería un ejercicio de humildad inusitado, una protesta pacífica y la propuesta de un nuevo modelo discursivo.

En cambio, en lo que respecta al habla femenina, callar es la norma a seguir, un imperativo tan prevaleciente que en ciertos contextos se sigue dando por sentado, al grado de rayar en la obviedad. En diversas culturas, las mujeres son un grupo más o menos silenciado cuya relación con el mundo debe estructurarse y adaptarse al modelo del grupo dominante que es el patriarcal, y que utiliza el poder discursivo justamente para formular y difundir a manera de ley esta relación de sujeción. Cito varios ejemplos emblemáticos de esta muy arraigada idea. Un antiguo proverbio griego sostiene que el silencio es el mejor adorno de la mujer; este precepto es promovido por Sófocles y

\footnotetext{
${ }^{1}$ La frase "final femenino" se utiliza tradicionalmente en poesía para designar aquellos versos que terminan con una palabra grave, es decir, una palabra en la cual la sílaba tónica es la penúltima, a diferencia de los masculinos, que terminan con una palabra aguda, con el acento en la última sílaba. En este artículo, sin embargo, la frase se utiliza de manera irónica para designar los finales que no son tales, los finales diferidos, relacionados en este caso con la voz femenina.
} 
reiterado nada menos que por Aristóteles, ambos figuras de máxima autoridad en el mundo clásico (Burke: 125). En la Biblia, otro influyente preceptor, san Pablo, afirma que la mujer debe aprender en silencio (1 Timoteo 2,11-12). Incluso en la modernidad temprana, los moralistas con frecuencia citaban estas fuentes para recomendar la reserva y la discreción en las mujeres, al tiempo que florecía un discurso que equiparaba a las parlanchinas con las prostitutas, y a las de lengua desenfrenada, con cortesanas que profesaban la incontinencia tanto lingüística como sexual. El silencio en cambio era el resultado de la modestia y la virtud, y en consecuencia, un reflejo de la honorabilidad de la mujer. Algunos recomendaban que las mujeres no hablaran con ningún hombre más que en presencia de sus maridos, y otros que ni siquiera con ellos, para no exasperarlos (Burke: 130-31). En ciertos contextos musulmanes, la voz femenina no debe llegar nunca a oídos masculinos porque se percibe como esencialmente seductora y conducente a la tentación (Brooks: 195).

El precepto del silencio conyugal se extiende al ámbito institucional cuando se establece una conexión semántica entre el silencio y el respeto a las figuras de autoridad. Así como el marido se representa en un lugar de superioridad moral y social con respecto a su esposa, el gobernante en la sociedad patriarcal detenta la autoridad suprema, y el silencio es obligatorio para todo el que se presente ante él; quien ose pronunciar palabra, deberá hacerlo ciñéndose a un estricto protocolo. En general, el espacio que rodea al gobernante es un espacio de silencio que crea un aura de solemnidad y veneración, receptivo exclusivamente para su palabra. Y si dicho gobernante es además el representante de la divinidad, el carácter del silencio que lo rodea se vuelve aún más complejo.

En el célebre cuento que sirve de marco a esa obra inmensa conocida como Las mil y una noches, se encuentra una situación extrema en donde entran en juego todos estos códigos. El sultán Shariar se descubre cornudo y, en venganza contra todas las mujeres, cada noche desposa a una nueva doncella sólo para ejecutarla al día siguiente, estableciendo así una asociación psicológica y social entre sexualidad y muerte, que da como resultado una perversión del deseo que pone en riesgo la estabilidad del estado. La respuesta automática que Shariar instituye después de cada acto sexual es de una descarada violencia contra las mujeres y constituye un despliegue de crueldad que escandaliza y aterra a la población.

Sherezada, la hija del visir, cuyo nombre según algunos significa "la hija de la ciudad" o "hija de aristócratas", es un portento intelectual que se propone poner fin a esta tiranía a través de su destreza para contar historias (y sobre todo para dejar de contarlas) (Cansinos, III: 1591). Para lograrlo se sirve de la argucia del suspenso, pues, so pretexto de desobedecer al sultán en su espantoso designio y para comunicarle que ella sabe que su vida está en sus manos, cada vez que amanece, ella calla. Paradójicamente, si la esposa adúltera de Shariar se valió de historias, es decir, mentiras, para engañar a su marido, Sherezada se valdrá también de historias para "curarlo" (MaltiDouglas: 39$)$. Lo interesante es observar el uso estratégico de la narración para los fines que ella se ha propuesto. 
El método de Sherezada consiste en establecer una dinámica que se asemeja mucho a la de la seducción, pues se finca en un juego de atracción (por medio de los cuentos) y negación o aplazamiento de la satisfacción con la promesa de placeres aún más deleitables para la siguiente noche. De esta manera logra desplazar el problema del deseo del espinoso terreno de la sexualidad en donde ella es la parte sometida al mundo oral de las historias que ella es capaz de regular y administrar. A través del acto narrativo, ella se constituye en una especie de maestra de Shariar; su misión es sustituir gradualmente, femeninamente, un tipo de deseo por otro: el deseo de desposar/ejecutar por el deseo de escuchar/aplazar la ejecución. En lugar de los efímeros contactos que tuvo con todas las esposas ejecutadas, Sherezada logra prolongar este contacto a través del cultivo del deseo narrativo en un marco temporal indefinido, haciendo un uso estratégico de la regla impuesta por Shariar, la misma regla que la mantiene sometida y bajo amenaza. Hay quienes sostienen que, en este sentido, Sherezada cumple la función de una maestra del deseo a la manera de una meretriz experta en un manual erótico, una de cuyas lecciones es postergar la culminación del acto sexual para derivar el máximo placer (Malti-Douglas: 40).

El desplazamiento del sexo al texto implica también un desplazamiento de lo visual a lo aural. El chasco inicial que se lleva el sultán al presenciar la orgía en la que participa su esposa adúltera con las demás mujeres y los esclavos negros es una experiencia voyeurística en la que él no tiene agencia inmediata y directa por estar excluido; pero las historias que cuenta Sherezada las recibe en calidad de auditor y, en apariencia, él siempre está en control de la situación. Las acciones vengativas del sultán son un pronunciamiento salvaje mediante el cual descarga su ira en contra de todo el género femenino; sólo si alguien lograra acallarlo dejaría de refrendar el mismo mensaje violento tantas veces reiterado. La empresa no es sencilla porque las narraciones de Sherezada están circunscritas a la feroz voluntad del gobernante agraviado. En estricto cumplimiento de los códigos antes descritos, ella solamente puede hablar con la venia de Shariar, y siempre bajo amenaza de muerte. Entonces, así como el discurso institucional es violento, totalitario, excluyente y cancelador, el discurso de quien está bajo amenaza está desacreditado y desarmado desde un principio. Ella sólo puede acumular capital simbólico mediante el uso estratégico del silencio.

Esta delicada operación se da en varios niveles: como mujer, el silencio es su obligación de género; como esposa, el silencio es su obligación conyugal; como súbdita, el silencio ante la autoridad es su obligación ciudadana. Más aún, en el mundo islámico de los cuentos, el habla femenina sólo está permitida en el harén - espacio enclaustrado que se traduce en mutismo social-, en el mercado, el lugar de abastecimiento en donde se busca procurar el bienestar masculino o familiar, y donde los intercambios son estrictamente comerciales, y en la cámara nupcial, el espacio íntimo donde ocurren tanto los encuentros sexuales como estas narraciones nocturnas. La noche es el tiempo en el que normalmente reina el silencio; es también el ámbito velado y acallado de los sueños; su oscuridad cobija el habla del inconsciente y permite la articulación de mensajes heterodoxos o incluso subversivos, bajo un lenguaje indirecto, cifrado o simbó- 
lico, un tipo de lenguaje que en este contexto se asocia con la mujer. Por ende, resulta pertinente sugerir que el día es masculino y la noche, femenina.

En algunas versiones de Las mil y una noches se pone énfasis en el hecho de que Sherezada es una mujer sumamente culta, que ha leído una enorme cantidad de libros y gracias a ello se desenvuelve tan bien como narradora. Y no hay duda de que una colección tan vasta de cuentos sólo pueda ser el fruto de una autoría múltiple y compleja. Lo interesante aquí es que, al construirse la identidad de Sherezada exclusivamente como recitadora de los cuentos, se le está presentando en realidad como una narradora casi totalmente desubjetivada en tanto que su yo no interviene en ningún momento a todo lo largo de la colección (Aravamudan: 57). La famosa estructura anidada de las historias - también descrita como de cajón o de cajas chinas- proporciona la justificación lógica y convencional para que Shariar le permita hablar, contar historias dentro de su propia historia: y es que en realidad Sherezada no dice nada. Las palabras que salen de su boca no son estrictamente suyas ni responden a sus circunstancias de manera directa. En ningún momento pide clemencia, ni habla de la crueldad del sultán hacia la población; jamás se describe a sí misma expresamente ante él como representante de todas las mujeres del reino que están padeciendo su tiranía. En una apuesta muy arriesgada en la que se juega la vida misma, ella se presenta como un mero vehículo del discurso, el soporte material viviente para que las palabras de otros tejan las redes que pudieran salvarla. No, su poder real no está en la palabra sino en el silencio.

Sherezada ha pedido a su hermana Diznarda que cada noche la despierte antes del amanecer y le pida que le cuente una historia. Aquí la palabra clave es amanecer, porque amanecer en este contexto equivale al silencio en la narración, un silencio expectante que cada vez puede conducir a un funesto desenlace; es la finalización (temporal, según sus deseos de supervivencia) del mundo imaginario, una peligrosa interrupción en donde todo puede suceder. La muerte de Sherezada es el fantasma que ronda atrás de cada narración y de cada suspensión de la misma; evoca también el terror de la narradora a quedarse sin nada que narrar. De hecho, Théophile Gautier publica en 1842 una novela titulada La noche mil dos, La Milleet deuxièmenuit, en la que Sherezada es ejecutada porque se le agotan la imaginación y las palabras. Edgar Allan Poe también imagina su muerte en un cuento titulado "El cuento mil dos de Sherezada", de 1845, "The Thousand-and-Second Tale of Sherezade", en el cual el sultán la manda ejecutar, no por haber callado sino por saber demasiado.

Para diferir la muerte, Sherezada incorpora su narración a la seguridad irrevocable de los ciclos cósmicos; ancla su vida a la sucesión de la noche y el día. Cada vez que clarea, el suspenso de la historia sin concluir se suma al suspenso en el que ella vive cada día que se suspende su ejecución, y va tejiendo una especie de cuerda floja por donde su vida se prolonga de manera precaria, por donde, literalmente, ésta pende de un hilo, un hilo narrativo. La verdad incontestable de que a toda noche le sigue un día hace parecer que las interrupciones narrativas sean el fruto de la obediencia al decreto real. No obstante, éstas ocurren en lugares estratégicos de la narración en los que la curiosidad de los escuchas está más azuzada que nunca. 
El final provisional de máximo suspenso, el llamado cliffhanger, se ha descrito como un clímax partido en dos (Nussbaum). En algunas versiones, Sherezada con frecuencia anuncia que la siguiente parte de la historia será aún más maravillosa que la que acaban de escuchar. Así, el cliffhanger vive de las promesas, prolonga el deseo, crea al público cautivo y poco a poco se convierte en la medida del tiempo. Las expectativas narrativas que se abren en la primera parte producen un efecto visceral poderoso que actúa como imán psicológico y que asegura la demanda para la siguiente ocasión.

Mucho se ha escrito acerca de la influencia de Las mil y una noches en la novela a partir del siglo XVIII en cuanto a los aspectos formales de la narración, en particular la estructura de historias anidadas en otras historias. En menor grado se ha estudiado su vinculación con su materialidad misma, en particular lo que se refiere a la relación entre la narración episódica y la novela por entregas. Las grandes novelas del siglo XIX son famosas por el uso que hacen del suspenso para fines comerciales; y si bien el novelista no estaba condenado a muerte, es un hecho que más y más autores vieron la posibilidad de ganarse la vida aplazando los finales de las historias, pues si comer era una necesidad hoy, mañana también. Charles Dickens y Thomas Hardy son dos de los ejemplos más notables, pues le ponían fin a una entrega en momentos cruciales para la trama, asegurando así la demanda de una siguiente entrega. En términos económicos, la fórmula funciona de maravilla.

Por ese motivo, se facilitó la aplicación de esta fórmula al ámbito de los nuevos medios de comunicación. Inicialmente en el radio, las radionovelas aprovechaban el tiempo limitado que se les asignaba para cortar el hilo de la narración o dramatización en momentos álgidos y así asegurar la audiencia del día siguiente. Sobra decir que con gran velocidad se incorporó la misma dinámica para introducir pausas comerciales en las que el público que escuchaba con tanta atención la obra radiofónica estuviera también expuesto a los anuncios comerciales que empezaron a "patrocinar" dichos programas. El traslado a la televisión se hace de manera automática en los famosos culebrones o telenovelas, cuyo nombre genérico en inglés alude precisamente a los silencios que se programan para dar cabida a los anuncios: soap operas, literalmente, óperas de jabón, dirigidas a mujeres supuestamente amantes de la limpieza doméstica. Además de las representaciones favorecidas por los programas mismos, se desarrollan mecanismos de representación generados por la publicidad que contribuyen a asegurar la demanda a largo plazo. Y si en los inicios de la televisión la fórmula del suspenso se aplicaba principalmente a las telenovelas, es decir, a programas de segunda categoría dirigidos a públicos femeninos sin ocupación profesional (al grado de convertirse en clichés fácilmente parodiados), en la actualidad es tan feroz la competencia entre los medios que se han desarrollado fórmulas para enganchar a los gustos más exigentes en horarios estelares. Algo similar ocurre en el cine, cuando se ven versiones cinematográficas de las novelas - sobre todo juveniles - seriadas. Y no es que la industria mediática esté condenada a muerte como Sherezada, pero el hecho es que si un programa o serie no es capaz de seducir a sus audiencias, muere. 
Además de estas implicaciones ideológicas inmediatas, la aplicación de la técnica del suspenso para la preservación de la vida en Las mil y una noches, sin embargo, tiene también un potencial filosófico fascinante. En el cuento del "Jardín de los senderos que se bifurcan" Borges imagina un libro infinito e inventa que a la mitad de Las mil y una noches Sherezada, "por una mágica distracción del copista", empieza a contar su propia historia (Borges: 574). Refieren que Italo Calvino se obsesionó con la idea, pero no encontró el cuento en cuestión por más que lo buscó en numerosas traducciones y versiones. Escribió en cambio Si una noche de invierno un viajero (Se una notted' inverno un viaggiatore, 1979), un relato sin fin en el que un lector perdido no hace más que comenzar a leer libros sólo para descubrir que les falta el final, y si encuentra algún ejemplar de repuesto, éste tiene un principio distinto. En esta novela figura un novelista (igual que en el cuento de Borges su Sherezada contiene a otra Sherezada), que quiere escribir un libro que contenga sólo el puro placer de la anticipación, un libro en el que el final esté infinitamente diferido (Burton: xviii). Según el esquema lógico que plantean estos relatos, el silencio no está tanto en el agotamiento del material como en la retención deliberada de los desenlaces, en un suspenso prolongado de manera indefinida. Un caso extremo en el que esto sucede lo tenemos en Tristram Shandy (17591767) de Laurence Sterne, una novela experimental inconclusa escrita en diez libros en donde rara vez se entrega lo que se promete: por ejemplo, el nacimiento del protagonista, anunciado desde la primera página, no ocurre sino hasta el tercer volumen, con un sinnúmero de historias independientes antepuestas. El diferimiento le hace escasas concesiones a la trama, y esto en sí mismo resulta ser una virtud.

En el nivel espiritual, los relatos de Sherezada también han originado interpretaciones muy sugerentes. Sherezada aparece aquí no como un personaje común y corriente, sino como un arquetipo femenino, heredero de un fondo mítico ancestral. Ella externaliza una esencia íntima que se relaciona con lo más profundo de la psique y funge como guía iniciática. Del mismo modo, el sultán Shariar encarna la conciencia individual en proceso de iniciación. La ejecución de las esposas se interpreta como el desembarazo de las partes mundanas de la psique; una a una las va descartando como se descartan las ilusiones y los deseos artificiales. El principio masculino del yo por fin renuncia a afirmar su virilidad para someterse al poder femenino de la narración, y posibilitar de este modo su propia transformación. El avance circular que producen los finales aplazados hace parecer que no hay ningún avance, pero en realidad se trata de una progresión espiral o laberíntica hacia el único desenlace posible del peregrinaje anímico: la transformación de la voluntad mundana (vengativa en este caso) en una voluntad trascendente.

En este contexto, Sherezada opera de noche, mientras que su hermana, que es la encargada de anunciar la aurora, representa la faceta diurna del alma. Los hechos sobrenaturales narrados en los cuentos contribuyen a crear la atmósfera de misterio que conmueve y estremece, y que pone al ego en contacto con lo desconocido, con lo jamás proferido. La noche es el tiempo de calma y de silencio en donde el alma ya no tiene las distracciones mundanas de la personalidad terrestre. Es en la noche oscura que el 
alma es mayormente receptiva; es de noche cuando se acalla el intelecto discursivo de la racionalidad cotidiana. Los cuentos de Las mil y una noches se constituyen entonces como un puente entre las riquezas ocultas en el subconsciente y la conciencia diurna en tanto que desarrollan la preciosa facultad del discernimiento. A lo largo de los casi tres años que se supone que dura esta educación, los hijos que Sherezada le ofrece al sultán para la consolidación de su perdón son el fruto de una iniciación exitosa. El alma iniciada vuelve a nacer tras la consumación definitiva del perdón (Bancourt: 44-45).

\section{Obras consultadas}

Aravamudan, Srinivas. Enlightenment Orientalism: Resistingthe Rise of the Novel. Chicago: Chicago University Press, 2012. Impreso.

Ballaster, Ross. Fabulous Orients: Fictions of the East in England, 1662-1785. Oxford: Oxford University Press, 2005. Impreso.

BAnCOURT, Pascal. Les Mille et une nuits et leurtrésor de sagesse. Escalaquens: Dangles, 2007. Impreso.

Borges, Jorge Luis. Obras completas I: 1923-1949. Buenos Aires: Emecé, 2007. Impreso.

Brooks, Geraldine. Nine Parts of Desire: The Hidden World of Islamic Women. Nueva York: Anchor, 1998. Impreso.

Burke, Peter. The Art of Conversation. Ithaca: Cornell University Press, 1993. Impreso.

BurTOn, Richard, trad. The Arabian Nights. Tales from A Thousand and One Nights. Nueva York: Modern Library, 2001. Impreso.

CAnsinos Assens, Rafael, trad. y notas. El libro de las mil y una noches. México: Aguilar, 1993. 3 tt. Impreso.

Foucault, Michel. El orden del discurso. Trad. Alberto González Troyano. Buenos Aires: Tusquets, 1992. Impreso.

Malti-Douglas, Fedwa. "Homosociality, Heterosexuality, and Sharazâd". Arabian Nights Encyclopedia. Ulrich MARZOLPH y Richard VAN LEEUWEN, eds. Santa Barbara, CA: ABC-CLIO, 2004. I. Pp. 38-42. Impreso.

Nussbaum, Emily. "Tune In NextWeek: The Curious Staying Power of the Cliffhanger". The New Yorker. Web. 30 de octubre de 2014. <http://www. newyorker.com/arts/critics/television/2012/07/30/120730crte_television nussbaum>. 